$5-1996$

\title{
Cultural Competence: Essential Measurements of Quality for Managed Care Organizations
}

\author{
Elizabeth Mackenzie \\ University of Pennsylvania, emackenz@gse.upenn.edu \\ Risa Lavizzo-Mourey
}

Follow this and additional works at: https://repository.upenn.edu/gse_pubs

Part of the Communication Commons, Education Commons, Health Policy Commons, Organization Development Commons, Public Administration Commons, and the Social Work Commons

\section{Recommended Citation}

Mackenzie, E., \& Lavizzo-Mourey, R. (1996). Cultural Competence: Essential Measurements of Quality for Managed Care Organizations. Annals of Internal Medicine, 124 (10), 919-921. Retrieved from https://repository.upenn.edu/gse_pubs/397 


\title{
Cultural Competence: Essential Measurements of Quality for Managed Care Organizations
}

\author{
Abstract \\ We are currently witnessing a radical change in the health care system in the United States as a result of \\ the managed care juggernaut. Driven by the imperative to stem increasing health care costs, managed \\ care seeks to save money by "managing" health care utilization and narrowing the choices available to \\ health care consumers. Although both cost-saving strategies are effective, they also present a potential \\ threat to quality of care. As HEDIS and other measures of quality are revised, physicians must establish \\ guidelines for quality of care that support the burgeoning managed health care environment. In \\ developing these guidelines and measures, two important trends must be acknowledged and addressed. \\ First, managed care was formerly confined mostly to middle class populations but now envelops many \\ more diverse and vulnerable groups, including Medicaid, Medicare, and minority populations [1]. Second, \\ providing care within a managed care environment requires attention to the population of "covered lives" \\ in addition to individual patients.

\section{Disciplines} \\ Communication | Education | Health Policy | Organization Development | Public Administration | Social \\ Work
}




\section{Cultural Competence: Essential Measurements of Quality for Managed Care Organizations}

$\mathrm{W}$ e are currently witnessing a radical change in the health care system in the United States as a result of the managed care juggernaut. Driven by the imperative to stem increasing health care costs, managed care seeks to save money by "managing" health care utilization and narrowing the choices available to health care consumers. Although both cost-saving strategies are effective, they also present a potential threat to quality of care. As HEDIS and other measures of quality are revised, physicians must establish guidelines for quality of care that support the burgeoning managed health care environment. In developing these guidelines and measures, two important trends must be acknowledged and addressed. First, managed care was formerly confined mostly to middle class populations but now envelops many more diverse and vulnerable groups, including Medicaid, Medicare, and minority populations (1). Second, providing care within a managed care environment requires attention to the population of "covered lives" in addition to individual patients.

Simultaneously, the demographic characteristics of the United States are rapidly changing. By the year 2000 , roughly $25 \%$ of the U.S. population will be members of "minority" groups (2). Projections suggest that by the year 2050 , ethnic subpopulations will make up $47.5 \%$ of the total U.S. population (2), and that by the year 2056 , whites will probably be a minority group (3). Furthermore, minority groups are not monolithic, and we must take into account the considerable diversity that exists within U.S. ethnic subpopulations (4). In addition, many of these subpopulations remain disproportionately represented in low-income categories (5), and this too must be factored into guidelines for quality of care.

Of course, the hardest part of this process is actually formulating a set of viable guidelines that will improve the ability of a managed care organization to meet high quality standards in all populations and that will translate into measures of accountability. Such an endeavor is fraught with pitfalls. But the first steps must be to acknowledge the necessity of creating these guidelines and to conceptualize the components of such guidelines.
On this basis, we conceptualize "cultural competence" as the demonstrated awareness and integration of three population-specific issues: health-related beliefs and cultural values, disease incidence and prevalence, and treatment efficacy. But perhaps the most significant aspect of this concept is the inclusion and integration of three areas that are usually considered separately when they are considered at all.

The value of each component is distinct. First, the importance of "cultural sensitivity" or "cultural appropriateness" in delivering health care to a culturally diverse patient population is undeniable, and it is recognized as one variable in the measurement of physician accountability (6). That belief systems play a critical role in medical care has long been acknowledged (7), but interest in the sociocultural aspects of health care has recently intensified as it becomes increasingly clear that the benefit of an approach to healing is often population specific ( 8 , 9). Failure to address the very real issues of crosscultural communication and variations in health beliefs in the clinical setting certainly threatens patient satisfaction and potentially threatens clinical outcomes. Furthermore, the socioeconomic divide that may exist between the culture of managed care systems and the cultures of vulnerable populations acts as a formidable nonfinancial barrier to care, and this too must be considered (10). Managed care has distinct values and expectations that emerged from and are reinforced by the dominant youth-oriented culture in the United States. The belief systems and perspectives of cultural subpopulations, which are equally valid, may give rise to health-related behaviors that clash with the expectations of the health plan. As they penetrate into Medicare, Medicaid, and minority populations, successful managed care organizations will attempt to negotiate these differences respectfully and proactively - while constantly measuring their own performance.

Second, we believe that effectively managing health care resources for any population requires an epidemiologic perspective. Because disease incidence varies among racial and ethnic subpopulations, managed care organizations that do not have accurate 
epidemiologic data with which to guide decisions about health education, screening, and treatment programs will probably not use their limited resources most effectively in addressing diseases most prevalent in their member population. For example, some subpopulations within the United States have a greater incidence of non-insulin-dependent diabetes mellitus (11). Others are afflicted by and die from asthma disproportionately (12). Still others, such as the Hmong Vietnamese, have a much greater risk for liver cancer than other cultural groups because of previous episodes of hepatitis. Providers who are not guided by such epidemiologic knowledge are much more likely to make errors in diagnosis and treatment, wasting resources and damaging lives (13). If acceptable standards of quality are to be maintained with fewer resources, managed care organizations must routinely incorporate epidemiologic information into their programs and resource allocation decisions and must hold providers accountable for implementing practice strategies to meet the needs of the "lives covered."

Third, a growing body of evidence indicates that the efficacy of treatments can vary among different populations and that it is critical that the expected differences be integrated into measurements of quality $(14,15)$. For example, some data indicate that responses to drugs such as angiotensin-converting enzyme inhibitors, diuretics, and $\beta$-blockers differ according to race $(16,17)$, and other data sug. gests that responses to $\beta$-adrenergic agonists differ in black and white patients with asthma (18). Although the cited studies highlight important differences in treatment response, they focus on individual patients, not on outcomes in entire populations. Clinical researchers are calling for increased efforts in exploring population-specific pharmacologic effects to help ensure accurate diagnosis of disease (15), as well as drug safety and efficacy for all populations (19). Effective managed care organizations that accept responsibility for all the populations they serve will be guided by an awareness of this issue and will maintain flexibility in diagnostic and treatment protocols or formularies. In an environment in which delivering the most cost-effective-not necessarily the cheapest-treatment for the populations served will determine the reputation and financial success of a managed care organization, more research and guideline development in this area are clearly needed.

By way of illustration, some important indicators of cultural competence for managed care organizations whose "covered lives" include many minorities might include the effectiveness of an outreach program for Puerto Rican adolescents with asthma in conjunction with population-based measures of restricted activity caused by asthma; the percentage of pregnant women of low socioeconomic status who attend $90 \%$ of their prenatal visits beginning in the first trimester; mammography rates among minority women; and member satisfaction with language and cultural translation (or brokering) services (20).

In conclusion, it is imperative at this juncture for the medical community to determine what constitutes quality of care-particularly for vulnerable populations-and to formulate comprehensive and viable guidelines for achieving high-quality care in all populations. We believe that the concept of cultural competence, when defined as the integration of three familiar concepts, generates new, powerful, and essential measures of high-quality care for populations. Issues of quality and oversight are especially salient in a health care environment in which increasing numbers of lower-income, culturally diverse, possibly vulnerable populations are moving to a system of care based on limited choice. By including cultural competence in assessments of quality and by implementing culturally competent systems of care, managed care organizations can make serious progress toward successfully meeting the health care needs of all U.S. populations.

\section{Risa Lavizzo-Mourey, $M D, M B A$ \\ Elizabeth R. Mackenzie, PhD \\ Institute on Aging \\ University of Pennsylvania School of Medicine \\ Philadelphia, PA 19104}

Requests for Reprints: Risa Lavizzo-Mourey, MD, MBA, Institute on Aging, 3615 Chestnut Street, Philadelphia, PA 19104.

Current Author Addresses: Drs. Lavizzo-Mourey and Mackenzie: Institute on Aging, 3615 Chestnut Street, Philadelphia, PA 19104.

Ann Intem Med. 1996;124:919-921.

\section{References}

1. Fisher RS. Medicaid managed care: the next generation? Acad Med. 1994; 69:317-22

2. United States. Bureau of the Census. Statistical Abstract of the United States. Washington, DC: U.S. Government Printing Office; 1995:19

3. Time 9 April 1990:28

4. Health Status of Minorities and Low-Income Groups. 3d ed. Washington, DC: U.S. Department of Health and Human Services, Public Health Service, Health Resources and Services Administration, Bureau of Health Professions, Division of Disadvantaged Assistance; 1991. DHHS no. 271-848/40085.

5. LaVeist TA. Segregation, poverty, and empowerment. Milbank Q. 1993:71: $41-64$

6. Emanuel U. A professional response to demands for accountability: practical recommendations regarding ethical aspects of patient care. Ann Intern Med. 1996;124:240-9.

7. Kleinman A, Eisenberg L, Good B. Culture, illness, and care: clinical lessons from anthropologic and cross-cultural research. Ann Intern Med. 1978;88 $251-8$.

8. Blackhall U, Murphy ST. Frank G, Michel V, Azen S. Ethnicity and attitudes toward patient autonomy. IAMA. 1995;274:820-5.

9. Carrese IA, Rhodes LA. Western bioethics on the Navajo reservation. Benefit or harm? JAMA 1995;274:826-9

10. Friedman E. Money isn't everything. Nonfinancial barriers to access. JAMA 1994:271:1535-8

11. Friedman EA. Diabetic nephropathy in blacks. Transplant Proc. 1993;25: $2431-2$. 
12. Fisher EB Jr, Sussman UK, Arfiken C, Marrison D, Munro J, Sykes RK, et al. Targeting high risk groups. Neighborhood organization for pediatric asthma management in the Neighborhood Asthma Coalition. Chest. 1994; 106(Suppl 4):2485-2595.

13. Hufford DJ. Gender, culture, and experience: a case of fatal, painful miscommunication [Presentation]. Human Diversity in Health Care. Philadelphia: University of Pennsylvania; 18 March 1996

14. Wood A. Zhou HH. Ethnic differences in drug disposition and responsiveness. Clin Pharmacokinet. 1991;20:350-73.

15. McDaniel DO, Alarcon GS, Pratt PW, Reveille JD. Most African-American patients with theumatoid arthritis do not have the rheumatoid antigenic determinant (epitope). Ann Intern Med. 1995;123:181-7
16. Lang CC, Stein CM, Brown RM, Deegan R, Nelson R, He HB, et al. Attenuation of isoproterenol-mediated vasodilatation in blacks. N Engl j Med. 1995:333:155-60.

17. Saunders E. Hypertension in African-Americans. Circulation. 1991;83:1465-7.

18. Koenig JQ. Costa LG, Kaylor G. Lymphocyte beta-adrenoceptors, asthma, and ethnicity [Letter]. Lancet. 1992;340:738

19. Kitler ME. Clinical trials and transethnic pharmacology. Drug Saf. 1994;11: 378-91.

20. Chrisman NJ, Maretzki TW, eds. Clinically Applied Anthropology: Anthropologists in Health Science Settings. Boston: D. Reidel; 1982.

(C) 1996 American College of Physicians 